\title{
Time-motion analysis of competitive surfers: Portuguese championship
}

(1D) Beatriz Minghelli ${ }^{1}$
(iD) Sara Paulino
(iD) Sara Graça ${ }^{1}$
(D) Inês Sousa ${ }^{1}$
(D) Priscilla Minghelli ${ }^{2}$

1. School of Health Jean Piaget Algarve - Piaget Institute - Algarve, Portugal 2. National Traumato-Orthopedics Institute - Avenida Brasil, 500 - Cep: $20940-070$ - Rio de Janeiro - RJ - Brasil

http://dx.doi.org/10.1590/1806-9282.65.6.810

\section{SUMMARY}

BACKGROUND: Time-motion analysis has been used to provide detailed insight into surfers' performance. This study evaluated surfers' activity times at the Portuguese surfing championship in order to account for the time spent in each surfing activity.

METHODS: Eighty-seven individually recorded videos of surfers were analyzed, showing their activity over the entire heat, and video analysis software was used to obtain each surfer's activity profile in the competition.

RESULTS: The results breakdown by time percentage show that the surfers were paddling $50.9 \%$ of the time, sprint paddling for wave $1.9 \%$, were stationary $34.1 \%$ of the time, wave riding 3.7\%, and involved in miscellaneous activities (e.g., duck diving, board recovery, etc.) $9.4 \%$ of the total time. Average times spent in each surfing activity were 18.6 seconds for paddling, 2.9 seconds for sprint paddling for a wave, 21.7 seconds for the stationary period, 11.5 seconds for wave riding, and 6.9 seconds for miscellaneous activities.

CONCLUSIONS: The data revealed that the most performed heat activity was paddling, allowing us to conclude that surfing is basically a long-arm paddling activity and that this activity constitutes a specific surfing competition demand, which in turn means that individual surfer's data can be used as a starting point for the development of tailored conditioning training programs.

KEYWORDS: Water Sports. Athletic Performance. Sports/physiology. Time and Motion Studies. Physical Exertion.

\section{INTRODUCTION}

Surfing has increased in popularity both at competitive and recreational levels on beaches worldwide, and so have the numbers of surfers in competitions ${ }^{2,3}$. According to the International Surfing Association $^{2}$, there are 35 million surfers in over 70 countries. The Portuguese Surfing Federation ${ }^{4}$ reports that there are about 10,000 federated surfers, 70 surfing clubs and 140 surfing schools in Portugal.
Surfing involves intermittent high-intensity bouts of all-out paddling, aimed at gaining enough momentum for the wave take-off (the moment in which the surfer stands up on the board to start to ride), intercalated with short recovery periods and repeated bouts of low-intensity paddling ${ }^{5,6}$. In a surfing session, it is necessary to perform the following movements: long periods of paddling out through breaking waves in or-

DATE OF SUBMISSION: 04-Dec-2018

DATE OF ACCEPTANCE: 10-Jan-2019

CORRESPONDING AUTHOR: Beatriz Minghelli

Instituto Piaget - Escola Superior de Saúde Jean Piaget / Algarve - Enxerim - 8300-025 - Silves - Portugal

Phone: 00 (351) 282440170

E-mail: beatriz.minghelli@silves.ipiaget.pt 
der to reach the take-off zone (the location where the wave is caught); repeated duck-diving (the surfer's pushing the board underwater, nose (the front tip of the board) first); repeated diving under oncoming broken waves and the corresponding breath holding; and brief periods of sprint paddling in order to catch a wave with power and speed, or to move around to find its best peak ${ }^{7}$. These movements are repeated many times throughout a surfing session and therefore require high muscular endurance, moderate-high cardio-respiratory endurance, recovery and anaerobic power of the upper torso ${ }^{8}$.

Competitive surfing consists of heats in which a maximum of 4 surfers participate, varying between 20 to 30 minutes in duration. Surfers' performance is judged based on the execution quality of a variety of maneuvers, and the main judging criterion is the performance of radical maneuvers in the most critical sections of a wave considering style, power, and speed'. Only 2 surfers of each heat progress to the next round. There are championships where the last rounds (quarterfinals, semi-finals, and finals) are disputed by 2 surfers only.

Prescribing training programs for surfers involves taking into account the duration of each activity and the corresponding metabolism required. Many different factors can influence the time spent in each surfing activity and its intensity, such as ocean currents, wind orientation, the size of the waves, water temperature ${ }^{9}$, the type of wave break, the frequency of waves, and the tides ${ }^{6,8}$.

Time-motion analysis refers to the frame-byframe examination of a surfer's video footage in a training session or in a competition, where timeand-distance data, movement patterns, frequency, mean duration and total time spent in activities are registered $^{8}$. Since the use of technology provides detailed and meaningful insight into surfing and surfers' performance ${ }^{3,8}$, evaluation and analysis of these data and their relation to the physiological demands placed on athletes during surfing can be further used as part of the competitive surfing coaching process, helping to design training programs and maximize athletes' performance.

Up to this date, time-motion analysis has been used in only three studies on competitive surfing ${ }^{1,5,10}$, in one study on surfing training ${ }^{11}$, and in another one on recreational surfing ${ }^{12}$.

Thus, the aim of this study is to establish the activity profile of Portuguese surfers at a Portuguese national competition heat in order to account for the times spent in each surfing activity and their mutual relationships.

\section{METHODS}

A cross-sectional descriptive survey was used for data collection in this study.

The study was approved by the RECI - Research in Education and Community Intervention Unit, the Piaget Institute's research unit, and by the Board of the Portuguese National Association of Surfers.

\section{Subjects}

The study population included was Portuguese male and female surfers competing in the "Allianz Figueira Pro", the third stage of the "MEO Surf League" Championship in Cabedelo Beach, Figueira da Foz, Central Portugal. Both competitions were organized by the Portuguese National Association of Surfers and the group Fire.

Sixty-four men and twenty-two women participated in the two championships, totaling 86 athletes.

A total of 50 heats was performed both in the men's and women's competition. Each heat was constituted by 2 to 4 athletes. In 3- or 4-surfer heats, only the 2 best scoring athletes moved forward to the next heat. In 2-surfer heats, only 1 moved forward.

Forty-eight rides were performed in the women's championship, and 126 in the men's, totaling 174 rides in the championship.

The sampling process was randomly stratified to cover half of the rides performed in the championship ( $\mathrm{n}=87$ rides).

\section{Heat Analysis}

Each surfer was videoed individually and for the entire duration of the heat, using a video camera. The recordings were obtained by four different evaluators, always positioned precisely in the same position - the place that offered the best view of the surfers in the sea and also minimized the periods in which they were submersed and their picture was lost.

The men's championship was divided into 3 rounds: Round 1, with 16 heats of 20 minutes each; Round 2, with 8 heats of 25 minutes each; and Round 3 , with 4 heats of 30 minutes each. Initially, there were 4 competing surfers in each heat, and the 2 with the best scores moved forward. In the quarterfinals, semi-finals and finals, there were only 2 ath- 
letes per heat (man-to-man), who competed for 30 minutes. There was a total of 35 heats in the men's competition.

In the women's championship, 15 heats were performed. Since there were much fewer women than men, there was only 1 round with 6 heats (Heat 1 to Heat 6). Two of the heats had 3 athletes competing against each other, and the other 4 had 4 athletes. The quarterfinals (Heats 7 to 10) were held with 3 athletes in each heat. In the semi-finals (Heats 11 to 12), there were 4 athletes in each heat. Then, new semi-finals were held (Heats 13 to 14) with 2 competitors in the same heat. The finals (Heat 15) were disputed by 2 athletes. The heats lasted for 20 minutes, with the exception of the semi-finals with two competitors and the finals, which lasted for 25 minutes.

The V-Note Video Analysis Software 2.1.2 was used to analyze each surfer's movement during the competition and to calculate the time spent in each activity.

The analyzed activities included:

- Paddling: alternating upper limbs movements towards the outside, or in search of the best wave peak;

- Sprint paddling for wave: the movement performed to catch the wave, recorded from the moment the surfer would turn towards the shore and begin to paddle forward with the forming wave until the start of the take-off (popup), regardless of whether or not the athlete achieved that goal;

- Stationary period: the time when the surfer stands up or sits on the board without any type of movement, including slow one-arm paddling to maintain the position in the take-off zone;

- Wave riding: the time between the take-off and the moment when the surfer's feet lose contact with the board;

- Miscellaneous activities: includes duck diving, recovery of the board after falling, getting in and out of the water, walking or running on the beach, the time when the surfer's image is lost due to the passage of a wave, and other non-specified activities.

The time pattern of each surfer's activity was analyzed, including the total and the average times of each activity mentioned above, and their frequency and occurrence percentage. All the analyses were performed by the same evaluator.

\section{Data analysis}

Descriptive statistics data were obtained regarding various surfing activities (paddling, sprint paddling for a wave, stationary, wave riding, and miscellaneous), including the average, standard deviation, range, and total duration.

Statistical analysis was performed with Statistical Package for Social Sciences (SPSS), version 23.0.

\section{RESULTS}

There were 174 rides in the championship, out of which 87 videos were made and analyzed.

Table 1 shows the duration (minutes:seconds) of each surfing activity performed during a competitive surfing heat, broken down by the 3 competition days (male and females competitors). In table 2, the same data are presented by gender.

Figure 1 shows the number of each surfing activity (in seconds; average \pm standard deviation), and figure 2 shows the percentage intervals (in seconds) of each activity for all the analyzed surfers during the heat.

\section{DISCUSSION}

To our knowledge, this is the first time-motion analysis study of a Portuguese championship. The obtained data revealed that paddling was the most practiced activity (51\%), as already observed in other studies ${ }^{1,5,10-12}$. However, the most significant percentage of this movement had a short duration (up to 15 seconds), while much longer paddling movements (between 121 to 300 seconds) registered significantly smaller percentages. This suggests that paddling is an activity with intercalary movements involving anaerobic metabolism, where resynthetisation of ATP is done through chemical reactions that do not require the presence of oxygen ${ }^{13}$.

Also, the data from the study by Mendez-Villanueva et al. ${ }^{1}$ showed that most of the paddling bouts $(60 \%)$ were performed at time intervals of between 1 and 20 seconds, a period similar to the one obtained in this study.

However, Minghelli et al. ${ }^{10}$ had previously analyzed a sample constituted by Portuguese children and adolescent surfers, and their data showed that the most frequent paddling time intervals were up to 5 seconds (39\%) and that paddling time intervals from 6 to 10 seconds corresponded to $26 \%$ of the total 
TABLE 1. TIME DURATION (MINUTES:SECONDS) OF SURFING ACTIVITIES BY DAY OF COMPETITION

\begin{tabular}{|c|c|c|c|c|c|c|}
\hline $\begin{array}{l}\text { Days of } \\
\text { competition }\end{array}$ & Surfing activities & Paddling & $\begin{array}{l}\text { Sprint paddle for } \\
\text { wave }\end{array}$ & Stationary & Wave riding & Miscellaneous \\
\hline \multirow[t]{4}{*}{ First day } & Average & 00:19.19 & $00: 03.28$ & 00:17.59 & $00: 12.46$ & 00:08.61 \\
\hline & Standard deviation & 00:28.97 & 00:01.60 & 00:22.13 & 00:06.96 & 00:13.35 \\
\hline & Range & 00:01-04:20.60 & 00:00.90-00:13.80 & 00:01.00-03:22.30 & 00:01.40-00:38.00 & 00:00.60 \\
\hline & Total time $\%$ & $56.4 \%$ & $2.2 \%$ & $24.9 \%$ & $3.3 \%$ & $13.1 \%$ \\
\hline \multirow[t]{4}{*}{ Second day } & Average & 00:19.69 & 00:02.79 & $00: 22.03$ & $00: 12.26$ & 00:06.25 \\
\hline & Standard deviation & $00: 26.91$ & 00:01.37 & $00: 29.02$ & 00:07.03 & 00:14.39 \\
\hline & Range & 00:00.30-03:46.20 & 00:00.90-00:08.70 & 00:00.80-03:55.50 & 00:01.40-00:40.00 & 00:00.10-02:37.10 \\
\hline & Total time \% & $50.2 \%$ & $1.5 \%$ & $36.9 \%$ & $4.0 \%$ & $7.4 \%$ \\
\hline \multirow[t]{4}{*}{ Last day } & Average & 00:12.73 & 00:02.56 & $00: 25.68$ & 00:09.06 & 00:03.05 \\
\hline & Standard deviation & $00: 15.23$ & 00:01.12 & $00: 27.90$ & 00:05.51 & 00:03.09 \\
\hline & Range & 00:00.80-02:36.40 & 00:00.20-00:07.70 & 00:00.20-03:51.30 & 00:01.50-00:28.60 & $00: 00.80-00: 46.80$ \\
\hline & Total time \% & $38 \%$ & $1.9 \%$ & $52.7 \%$ & $3.8 \%$ & $3.7 \%$ \\
\hline \multirow[t]{4}{*}{ All days } & Average & 00:18.06 & 00:02.96 & $00: 21.07$ & $00: 11.54$ & 00:06.99 \\
\hline & Standard deviation & 00:26.14 & 00:01.46 & $00: 26.34$ & 00:06.79 & $00: 12.80$ \\
\hline & Range & 00:01.02-04:20.60 & 00:00.20-00:13.80 & 00:00.50-03:55.50 & 00:01.40-00:40.00 & 00:00.10-03:11.60 \\
\hline & Total time $\%$ & $50.9 \%$ & $1.9 \%$ & $34.1 \%$ & $3.7 \%$ & $9.4 \%$ \\
\hline
\end{tabular}

TABLE 2. TIME DURATION (MINUTES:SECONDS) OF SURFING ACTIVITIES BY GENDER

\begin{tabular}{l|l|l|l|l|l|l} 
Categories & \multicolumn{2}{l}{ Surfing activities } & \multicolumn{2}{l}{ Paddling } & $\begin{array}{l}\text { Sprint paddle for } \\
\text { wave }\end{array}$ & \multicolumn{2}{l}{ Stationary } & \multicolumn{2}{l}{ Wave riding } & Miscellaneous \\
\hline \multirow{3}{*}{ Men surfers } & Average & $00: 18.11$ & $00: 02.89$ & $00: 22.10$ & $00: 11.64$ & $00: 06.89$ \\
\cline { 2 - 7 } & Standard deviation & $00: 28.15$ & $00: 01.49$ & $00: 27.24$ & $00: 06.90$ & $00: 19.55$ \\
\cline { 2 - 7 } & Range & $00: 00.30-09: 51.00$ & $00: 00.20-00: 13.80$ & $00: 00.20-03: 55.50$ & $00: 01.40-00: 40.00$ & $00: 00.10-09: 41.10$ \\
\cline { 2 - 7 } & Total time \% & $45.1 \%$ & $1.6 \%$ & $33.7 \%$ & $4.4 \%$ & $15.3 \%$ \\
\hline \multirow{4}{*}{$\begin{array}{l}\text { Women } \\
\text { surfers }\end{array}$} & Average & $00: 18.70$ & $00: 03.31$ & $00: 14.91$ & $00: 11.54$ & $00: 10.65$ \\
\cline { 2 - 7 } & Standard deviation & $00: 26.83$ & $00: 01.28$ & $00: 19.05$ & $00: 06.22$ & $00: 29.90$ \\
\cline { 2 - 7 } & Range & $00: 00.40-03: 13.50$ & $00: 00.90-00: 06.90$ & $00: 01.10-02: 32.30$ & $00: 01.40-00: 27.50$ & $00: 00.80-07: 38.60$ \\
\cline { 2 - 7 } & Total time \% & $55.6 \%$ & $2.0 \%$ & $21.2 \%$ & $1.9 \%$ & $19.3 \%$ \\
\hline
\end{tabular}

paddling time. The discrepancy of these results may be due to age and skill differences between the samples, as well as to external conditions.

As for the time intervals in sprint paddling to catch the wave, the majority was also of short duration (up to 2 seconds), meaning that for the execution of this activity the same anaerobic metabolism is requested (phosphatic system) because it involves fast and vigorous movements ${ }^{13}$.

The wave riding time was only $3.7 \%$ of the total time. Here, however, some quite diverse results have also been reported: Minghelli et al. ${ }^{10}$ data revealed a wave riding time of only $3 \%$ of the total time; Mendez-Villanueva et al. ${ }^{1}$ showed it to be $3.8 \%$ in competing surfers; Farley et al. ${ }^{5}$ reported $8 \%$ in surfers from the current top 30 surfers in New Zealand; Meir et al. ${ }^{12}$ reported $5 \%$ of wave riding in the total of one hour of recreational surfing, and Secomb et al. ${ }^{11}$ revealed $2.5 \%$ in a two-hour surfing training session.
The differences may be associated with the fact that different conditions of surfing were evaluated: free surfing and competition, and different athletes' age groups and skills. In a competition, the athlete must select the best waves to obtain the highest score in the time allocated to the heat, so if they spend their time catching a lot of waves without much quality, they lose their heat time paddling back to the peak. On the other hand, during a training session or in free surfing, the athlete does not have this concern, being able to catch a greater number of waves without having to select them or to wait for the best wave to set to surf. During a competition, the surfers are judged by the two best-scored waves, and not by the number of waves caught. Moreover, the athlete has to make some tactical decisions considering the opponent's score or wave selection, and these options may also influence the total time surfers spend in the above-mentioned activity ${ }^{5}$. 


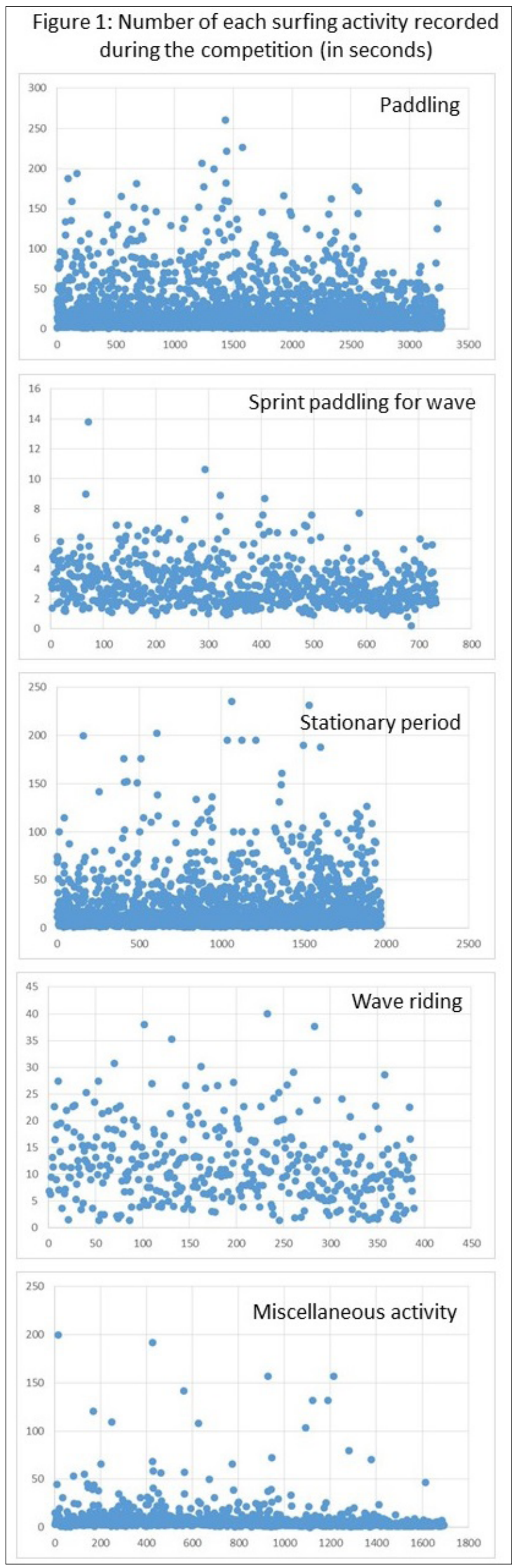

Figure 2: Percentage intervals of each activity recorded during the competition (in seconds)
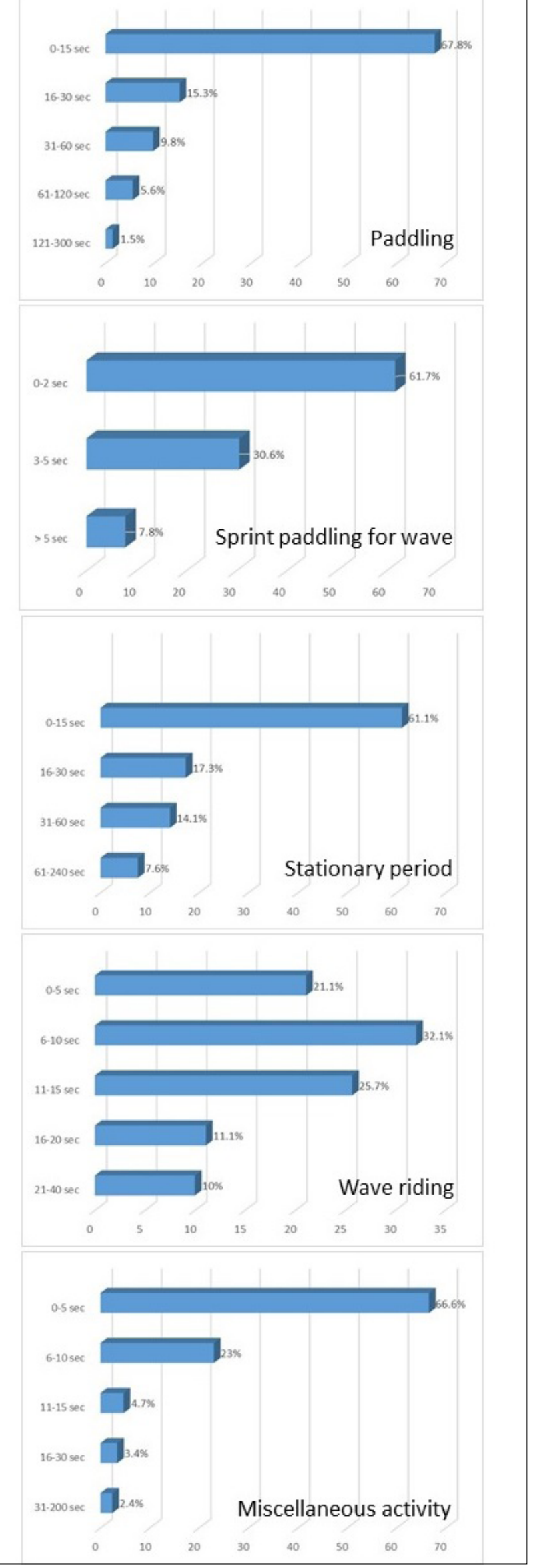
Regarding the age and skill difference, the competitive competence of athletes in the study by Minghelli et al. ${ }^{10}$ and in this study is also different and may have influenced the results obtained since in the former the sample consisted of young regional athletes, while in the latter it involved elite athletes of Portugal.

The average length of wave riding in the present study was 11.5 seconds, similar to the data obtained by Mendez-Villanueva et al. ${ }^{1}$ - an average of 11.6 seconds for a sample of elite professional surfers ranked in the World Qualifying Series (WQS). On the other hand, the average wave riding time obtained in the Minghelli et al.'s study ${ }^{10}$ was only 4.4 seconds. These results cannot be duly compared since they involved different samples (top Portuguese surfers vs. children and adolescent surfers).

By analyzing the time interval of each activity mentioned above, it can be verified that there is little disintegration of glycogen into lactic acid since this type of metabolism is present in short term activities. Lactic acid is a co-product of anaerobic glycolysis, and when it reaches high levels in muscles and blood, it causes muscle fatigue ${ }^{13}$.

Now regarding the time spent in the stationary period, the data of this study show a different value (34\% of the total time) when compared to other studies. Thus, Mendez-Villanueva et al.'s study' ${ }^{1}$ revealed $42 \%$ of the total time in stationary activity, and Farley et al. ${ }^{5}$ showed $28 \%$. Finally, Minghelli et al.'s study ${ }^{10}$ involving younger surfers registered values of only $13 \%$ for the stationary period. The differences may suggest that stationary time depends on several external factors, such as the motivation of the athlete and the time between oncoming waves.

Regarding the competition analyzed here, which took place over three days, it has to be noted that it had very different external conditions on different days. On the last day, it even happened that some of the heats had to be postponed because not even the minimum conditions for surfing had been met. Accordingly, the stationary period was the highest on the last day (53\% vs. $25 \%$ and $37 \%$ on the previous days, respectively). Different tides, wave breaking, and wind directions provided very different swells on the different days at the same beach.

However, Secomb et al. ${ }^{11}$ revealed values of 53\% for the stationary period when analyzing a two-hour surfing training session, and Meir et al.'s study ${ }^{12}$ involving recreational surfers obtained the value of
$44 \%$. The difference shows that surfers are more active in a competition than when training or doing free surfing.

Also, most of the stationary period times obtained in this study were very short (up to 15 seconds), revealing that the athletes needed only a brief recovery period and were always looking for the best sea conditions and, if the external conditions allowed them, to kept moving during the heat. Also, Mendez-Villanueva et al. ${ }^{1}$ revealed that most surfers had stationary intervals of up to 10 seconds, followed by intervals between 11 and 20 seconds, and Minghelli et al. ${ }^{10}$ showed a period that was even shorter, with values of up to 5 seconds.

Finally, the time spent on miscellaneous activities (e.g., duck diving, recovering the surfboard, etc.) accounted for only $9.4 \%$ of the total heat time in this study. This value is clearly lower than the $16 \%$ reported by Meir et al. ${ }^{12}$, or the $23 \%$ observed by Minghelli et al. ${ }^{10}$. However, Mendez-Villanueva et al.'s study ${ }^{1}$ showed only $2.2 \%$ of the total time.

The vast majority of the time intervals in these activities of up to 5 seconds may reveal greater athletes' dynamism. Most of the miscellaneous activities in Minghelli et al.'s heat analysis ${ }^{10}$ registered values of up to 30 seconds. This difference may again be attributed to technical and physical conditions of the athletes in each sample and external conditions of each competition day. Indeed, miscellaneous activities depend on sea conditions, currents, wave frequency periods, and the level of motivation of the athlete. Thus, in the analyzed competition, some athletes even chose to leave the water and return to the place where the entrance was facilitated by the current, and this time-consuming activity was also included in the miscellaneous activities.

In fact, the data obtained in this study only provides information on the specific population, place, and conditions studied in the videoed competition since multiple surfing conditions and environmental factors, such as swell size, inconsistent surfing, currents, wave length or frequency, beach break or reef break, competing for waves, surfers' technical and physical condition and motivation all influence the time lengths and percentages surfers spend in each activity.

The frequency and duration of surfing activities and the ratio between work and rest periods are important variables to know the metabolisms involved in the activity, but nowadays, there is also specific 
equipment for measuring these variables, which can provide more accurate information about the type of metabolism involved. Some sports analyses have also included the use of global positioning system (GPS) technology, heart rate control, and estimated energy expenditure of the surfing activity in order to determine the intensity of the activity and the metabolism required. However, the aquatic environment is hostile to electronic equipment, water-proof equipment is expensive, and some athletes also find that monitoring during competition interferes with their performance during the heat.

Nonetheless, identification of physically highly demanding periods is important for surfing as it can provide relevant data to help understand specific surfing competition requirements, and can be used as a reference to adapt training programs to the temporal work demands of a surfing competition and to develop specific conditioning and appropriate training protocols.

However, it is necessary to carry out additional studies at the Portuguese national level, involving elite athletes, both adult and young surfers, for a better analysis of the total time of the surfing activity since it depends on unpredictable variables of the surfing environment.

\section{CONCLUSION}

The data obtained in this study revealed that, for this specific sample of competing surfers, the most performed activity during the heats was paddling, while the time spent on wave riding was only $4 \%$ of the total time of the heat. Thus, the results showed that surfing consists mostly of long-arm paddling, which provided valuable information for coaches about specific demands of the surfing competition, and which can be further used to develop conditioning training programs according to the surfer's specific demands.

The results of this study also showed that surfing is an intermittent activity that is characterized by a large variability of the times of the activities involved and that surfing activities seem to be very much influenced by external environmental factors, as well as by the surfer's motivation and technical skills.

\section{Conflict of interest}

none

\section{Funding sources}

This study is financed by national funds through FCT - Foundation for Science and Technology, I.P., in the scope of the project UID/Multi/04587/2013; Research in Education and Community Intervention (RECI)

\section{Acknowledgment}

National Association of Surfers; Tiago Machado surfer; Henrique Piki Gomes surfer; Surf Bar - Cabedelo beach bar; Ph.D. Arijana Medvedec by the language editing, and proofreading.

\section{RESUMO}

INTRODUÇÃo: A análise temporal dos movimentos tem sido usada para fornecer informações detalhadas sobre o desempenho dos surfistas. O objetivo deste estudo foi avaliar os tempos das atividades dos surfistas em um campeonato português de surfe, em nível nacional, a fim de contabilizar o tempo gasto em cada movimento do surfe.

MÉTODOS: Foram realizadas 87 filmagens individuais dos surfistas, durante os diversos heats que decorreram ao longo da competição, sendo estas analisadas com um software para obtenção do perfil das atividades dos surfistas na competição.

RESULTADOS: Os dados obtidos revelaram que o movimento de remada correspondeu a 50,9\% do tempo total despendido na competição, a remada para apanhar a onda consistiu em 1,9\%, o período estacionário compreendeu 34,1\%, o ato de apanhar a onda de apenas 3,7\% e outras atividades (bico de pato, recuperação da prancha etc.) envolveram 9,4\% do tempo total da competição. Os tempos médios gastos em cada atividade de surfe foram de 18,6 segundos para remada, 2,9 segundos para remada para apanhar a onda, 21,7 segundos para o período estacionário, 11,5 segundos para andar de onda e 6,9 segundos para outras atividades.

CONCLUSÕES: Os resultados revelaram que o surfe consiste em uma atividade que abrange longos períodos de remada, envolvendo uma demanda energética específica para a prática desse esporte. Os dados obtidos são necessários para o desenvolvimento de estratégias de treinamento que levem em consideração o tempo gasto em cada atividade do surfe e o consequente metabolismo energético envolvido, a fim de que se efetive uma prescrição adequada de um programa de treinamento.

PALAVRAS-ChAVE: Esportes aquáticos. Desempenho atlético. Esportes/fisiologia. Estudos de tempo e movimento. Esforço físico. 


\section{REFERENCES}

1. Mendez-Villanueva A, Bishop D, Hamer P. Activity profile of world-class professional surfers during competition: a case study. J Strength Cond Res. 2006;20(3):477-82.

2. International Surfing Association. [cited 2018 Oct 10]. Available from: https://www.isasurf.org/.

3. Redd MJ, Fukuda DH. Utilization of time motion analysis in the development of training programs for surfing athletes. Strength Conditioning ). 2016;38(4):1-8.

4. Portuguese Surfing Federation. [cited 2018 Oct 10]. Available from: https://www.surfingportugal.com/cms/index/view/gid/9917.

5. Farley OR, Harris NK, Kilding AE. Physiological demands of competitive surfing. I Strength Cond Res. 2012;26(7):1887-96.

6. Mendez-Villanueva A, Bishop D. Physiological aspects of surfboard riding performance. Sports Med. 2005;35(1):55-70.

7. Lowdon B. Fitness requirements for surfing. Sports Coach. 1983;6:35-85.
8. Farley ORL. Competitive surfing: a physiological profile of athletes and determinants of performance [Master of Sport and Exercise Thesis]. Auckland: Auckland University of Technology; 2011.

9. Moraes GC, Guimarães AT, Gomes AR. Analysis of injuries' prevalence in the surfers from Paraná seacoast. Acta Ortop Bras. 2013;21(4):213-8.

10. Minghelli B, Graça S, Paulino S, Sousa I. Time-motion analysis of young competitive surfers: southern Portugal. J Sports Med Doping Stud. 2017;7:3. https://doi. org/10.4172/2161-0673.1000194, 2017.

11. Secomb JL, Sheppard JM, Dascombe BJ. Time-motion analysis of a 2-hour surfing training session. Int J Sports Physiol Perform. 2015;10(1):17-22.

12. Meir R, Lowdon BJ, Davie AJ. Heart rates and estimated energy expenditure during recreational surfing. I Sci Med Sport. 1991;23(3):70-4.

13. McArdle W, Katch F, Katch V. Exercise physiology: nutrition energy, and human performance. $8^{\text {th }}$ ed. Baltimore: Wolters Kluwer Health; 2015. 